\title{
Literatura e infância: entre filosofia, história e "despropósitos"
}

Márcia Cabral da Silva"

A literatura pode ser definida como exercício criativo que ocorre por intermédio da palavra. Trata-se da possibilidade de transfiguração do real em matéria fictícia. Nesta chave, retoma-se a esfera criativa que dialoga com o estranhamento, com a indagação e, por assim dizer, com a dimensão filosófica da linguagem.

Benjamin $(1984,1987)$ já tratava em seus ensaios dos livros infantis e questionava a função instrumental que adquiriram nas sociedades industrializadas. Tecia severa crítica em relação à utilidade dos livros ficcionais infantis, ao empobrecimento das ilustrações, de um lado. De outro, apontava a inexorável aproximação dos livros infantis das gramáticas orientadas pelos pedagogos. Todavia, os seus escritos convidariam, por outro viés, à indagação: como reencontrar o caráter artesanal de um objeto que passara a responder ao pragmatismo, à utilidade de todas as coisas, tal como os demais objetos que deveriam atender em primeiro lugar a uma lógica da produção no desenvolvimento das sociedades capitalistas? Nesse sentido, o caráter artístico e o convite à imaginação criadora haviam sido transferidos a um segundo plano?

Em uma chave semelhante, Vygotsky (1987) apontava para a importância da imaginação e da arte no período que se convencionou denominar infância. Segundo o autor, fantasia e realidade consistiriam em dimensões complementares, e não polos excludentes, como se costuma indicar na educação das crianças. Ademais, segundo essa linha de consideração, na vida diária, seria possível exercitar plenamente a imaginação criadora.

Neste artigo, retomam-se algumas dessas reflexões no âmbito da relação entre literatura e infância. Se a experiência e a história são derivadas da fratura entre a infância do homem e a emergência da linguagem, na perspectiva filosófica indicada por Agamben (2005), como essa fratura ocorreria na literatura? Em que condições a linguagem literária permitiria ascender à história e à experiência? Essas são algumas questões gerais sobre as quais se busca refletir neste estudo. Trata-se de pensar sobre a dimensão filosófica da linguagem em diálogo com obras

\footnotetext{
${ }^{1}$ Doutora em teoria e história literária e professora da Universidade do Estado do Rio de Janeiro (UERJ), Rio de Janeiro, RJ, Brasil. E-mail: marciacs@ ism.com.br
} 
literárias contemporâneas que trazem ao primeiro plano a infância. De um lado, desenvolve-se uma reflexão sobre a relação ficção e infância, com especial acento na produção protagonizada por personagens crianças. De outro, ressalta-se a análise de estratégias literárias capazes de causar estranhamento em relação ao caráter descritivo e comunicativo da linguagem cotidiana. Com vistas a desenvolver o estudo, privilegiam-se as seguintes obras: Exercícios de ser criança (1999) e Memórias inventadas: a infância (2003), de Manoel de Barros.

\section{Linguagem literária e filosofia da linguagem}

No descomeço era o verbo.

Só depois é que veio o delírio do verbo.

O delírio do verbo estava no começo, lá onde a criança diz: eu escuto a cor dos passarinhos.

A criança não sabe que o verbo escutar não funciona para cor, mas para som.

Então se a criança muda a função de um verbo, ele delira.

E pois.

Em poesia que é voz de poeta, que é a voz de fazer nascimentos O verbo tem que pegar delírio (Barros, 2010, p. 301).

O poeta Manoel de Barros comparece neste estudo pela importância de sua obra como matéria literária de um modo geral. Poeta de trajetória singular. Nasceu à beira do Rio Cuiabá em 1916, estudou no Rio de Janeiro ao longo de sua formação e, anos depois, passou a residir em Campo Grande, Mato Grosso do Sul. Faleceu em 2014 em meio aos animais e à quietude de sua fazenda. Chama a atenção o fato de ter sido advogado, fazendeiro e poeta. A associação entre as três profissões é rara. Sua revelação poética ocorreu aos 13, como sugere também Manoel de Barros em "O poeta": "Vão dizer que não existo propriamente dito. Que sou um ente de sílabas. Vão dizer que eu tenho vocação pra ninguém. Meu pai costumava me alertar: quem acha bonito e pode passar a vida a ouvir o som das palavras ou é ninguém ou zoró. Eu teria treze anos" (Barros, 2010, p. 390). Autor de vários poemas, foi agraciado com prêmios literários no Brasil e no exterior. Destaca-se, sobretudo, pelo esmero estético com a palavra, como pode ser notado no conjunto de sua escrita. Todavia, no que diz respeito às relações entre literatura, infância e experiência, limites das 
reflexões neste estudo, comparecem, em particular, Memórias inventadas: a infância e o livro infantil Exercícios de ser criança.

Considere-se, de início, o fragmento anteriormente citado, extraído de O livro das ignorãças (ver Barros, 2010). O material pode ser definido como exercício criativo, que ocorre por meio da palavra trabalhada artisticamente. Trata-se, de modo particular, da possibilidade de transfiguração do real em matéria fictícia. Acompanha-se com o poeta o exercício sugerido. Trata-se, ali, da percepção da poesia e do conceito sobre o que seja poesia, formulado por intermédio de metalinguagem. No início - sugere-se: na origem da humanidade - era o verbo. Todavia, a partir da emergência da literatura, torna-se possível "o delírio do verbo". Literatura ou, se assim desejarmos, a arte da palavra, ancora-se na criação humana, pois, se toma forma, vale-se do trabalho criativo do artista. Não é se estranhar tal assertiva, pois "em poesia que é voz de poeta, que é voz de fazer nascimentos - O verbo tem que pegar delírio."

Nesta chave, retoma-se com Manoel de Barros a esfera criativa que dialoga com o estranhamento, com a indagação e, por assim dizer, com a dimensão filosófica da linguagem. Mas por que a criação, neste caso, se aproximaria da filosofia da linguagem? A leitura atenta do poema que segue sugere pistas. Convém ampliar, portanto, a comparação entre literatura e dimensão filosófica da linguagem, observando-se "Cabeludinho", extraído de Memórias inventadas: a infância:

\section{Cabeludinho}

Quando a Vó me recebeu nas férias, ela me apresentou aos amigos. Este é meu neto. Ele foi estudar no Rio e voltou de ateu. Ela disse que eu voltei de ateu. Aquela preposição deslocada me fantasiava de ateu. Como quem dissesse no Carnaval: aquele menino está fantasiando de palhaço. Minha avó entendia de regências verbais. Ela falava de sério. Mas todo-mundo riu. Porque aquela preposição deslocada podia fazer de uma informação um chiste. E fez. E mais: eu acho que buscar a beleza nas palavras é uma solenidade de amor. E pode ser instrumento de rir. De outra feita, no meio da pelada um menino gritou: Dislimina esse, Cabeludinho. Eu não disliminei ninguém. Mas aquele verbo novo trouxe um perfume de poesia à nossa quadra. Aprendi nessas férias a brincar de palavras engavetadas. Aquela que não pode mudar de lugar. Aprendi a gostar mais das palavras pelo que elas entoam do que pelo que elas informam. Por depois ouvi um vaqueiro a cantar com 
saudade: Ai morena, não me escreve/ que eu não sei $a$ ler. Aquele a preposto ao verbo ler, ao meu ouvir, ampliava a solidão do vaqueiro (Barros, 2003, s.p., grifos nossos).

A relação entre literatura e filosofia da linguagem sugerida no excerto transcrito anteriormente emerge, primeiro, de um deslocamento deliberado em relação à sintaxe: inserir a preposição de coloca a ordem das palavras pelo avesso. Por derivação, causa estranhamento. Ao se estranhar, pergunta-se, tornando possível jogar com significante e significado. "Voltar de ateu" permite a criação de outros sentidos, buscar a beleza da palavra, criar o chiste. De modo a ilustrar a argumentação, o eu lírico acrescenta que: "Minha avó entendia de regências verbais. Ela falava de sério. Mas todo-mundo riu." Ademais, verifica-se que o texto literário não se limita a descrever o mundo ao qual se refere. A ficção elaborada por Manoel de Barros, ao afastar-se das normas tradicionais da linguagem, parece criar uma realidade que ganha existência e diz o mundo. Em outras palavras, reconhece-se que o poeta opera com recursos inusitados da linguagem, imprimindo-lhe contornos literários e filosóficos por meio da transgressão em relação aos padrões convencionais da narrativa. Isto posto, trata-se, com Manoel de Barros, de acompanhar uma narrativa híbrida, entre prosa e poesia, que força a linguagem a se voltar para um movimento sobre si mesma, a transgredir.

\section{Brincadeiras}

No quintal a gente gostava de brincar com palavras mais do que de bicicleta. Principalmente porque ninguém possuía bicicleta. A gente brincava de palavras descomparadas. Tipo assim: $\mathrm{O}$ céu tem três letras, o sol tem três letras, o inseto é maior. O que parecia um despropósito. Para nós não era despropósito. Porque o inseto tem seis letras e o sol só tem três. Logo o inseto é maior. (Aqui entrava a lógica?). Meu irmão que era estudado falou quê lógica quê nada. Isso é um sofisma. A gente boiou no sofisma. Ele disse que sofisma é risco n'água. Entendemos tudo (Barros, 2003, s.p.).

Em ensaio emblemático sobre filosofia da linguagem, Bakhtin (1994) também reflete sobre noções semânticas de maneira interessante. Segundo o autor russo, o problema da significação é um dos mais complexos no campo dos estudos linguísticos, visto que o tema da enunciação estará sempre em jogo nas cadeias das interações verbais. Com o objetivo de explicitar o problema da significação, o autor discute exaustivamente as noções de tema e de significação. Segundo ele, o tema da enunciação é 
individual e não reiterável, pois é determinado pelas condições históricas e sociais de produção do enunciado. Contudo, no interior do tema, subjaz a significação, que, diferentemente do tema, constitui os elementos reiteráveis e idênticos da enunciação cada vez que são produzidos (Bakhtin, 1994, p. 129). Em uma palavra, há possibilidades semânticas infinitas na história, o que favorece o surgimento de formas novas de percepção do mundo, conforme o poeta enuncia.

A linguagem literária referida apresenta, pois, inusitadas possibilidades de percepções de mundo. Com Manoel de Barros, a significação das palavras é deliberadamente ampliada, visto que as palavras em estado de dicionários são forçadas aos deslocamentos poéticos. Ademais, os deslocamentos convidam a indagar. Não seria essa uma atividade filosófica por excelência? Atividade para a qual o poeta Manoel de Barros convidanos uma vez mais em "Cabeludinho". Desta feita, brincando com palavras designadas por "engavetadas" e com os neologismos:

Dislimina esse, Cabeludinho. Eu não disliminei ninguém. Mas aquele verbo novo trouxe um perfume de poesia à nossa quadra. Aprendi nessas férias a brincar de palavras engavetadas. Aquela que não pode mudar de lugar. Aprendi a gostar mais das palavras pelo que elas entoam do que pelo que elas informam. Por depois ouvi um vaqueiro $a$ cantar com saudade: Ai morena, não me escreve/ que eu não sei $a$ ler. Aquele $a$ preposto ao verbo ler, ao meu ouvir, ampliava a solidão do vaqueiro (Barros, 2003, s.p., grifos nossos).

Para além do deslocamento em relação ao pensamento linear, à linguagem meramente informativa, com frequência alçada à esfera instrumental, a literatura pode ser um modo singular de permitir ascender à história e à experiência. Manoel de Barros, no desenvolvimento de seus poemas, permite o acesso à experiência, operando por deslocamentos. Acresça-se ao seu estilo o jogo de palavras, estratégia que força outros deslocamentos estéticos nos limites da construção literária elaborada pelo poeta. Assim, lemos que:

\section{$\mathrm{O}$ apanhador de desperdícios}

Uso a palavra para compor meus silêncios. Não gosto das palavras fatigadas de informar. Dou mais respeito às que vivem de barriga no chão tipo água pedra sapo. Entendo bem o sotaque das águas. Dou respeito às coisas desimportantes. Prezo insetos mais que aviões. Prezo a velocidade das tartarugas mais que as dos mísseis. Tenho em mim um atraso de nascença. Eu fui 
aparelhado para gostar de passarinhos. Tenho abundância de ser feliz por isso (Barros, 2003, s.p.).

Nota-se, da mesma forma, que a experiência e a história são derivadas da fratura entre a infância do homem e a emergência da linguagem, na perspectiva filosófica indicada por Agamben (2005). O homem, condenado a ser in-fans, aquele que não aprendeu a falar, descobre a palavra. De tal modo, esse evento permite que linguagem e história coincidam como momento inaugural: aquele que emerge com o nascimento da linguagem no homem. Ademais, permite-nos pensar na possibilidade de uma fratura no curso de uma concepção histórica marcada pelo emudecimento ou, ao revés, pela evolução meramente comunicativa da humanidade. Como, então, essa alegoria da fratura ocorreria na literatura? Em que condições a linguagem literária permitiria ascender à história e à experiência?

\section{Linguagem literária e experiência}

A experiência pode ser pensada como os acontecimentos narrados, os lugares pelos quais passamos em tempos remotos, os espaços que habitamos no tempo presente. Todavia, creio que o conceito deva ser refletido, ele próprio, em sua historicidade. Exercício interessante pode ser realizado a partir de outro deslocamento: o espaço temporal. Lembremos, por exemplo, as rupturas históricas. Neste sentido, observamos que a experiência de vida na passagem do século XIX ao XX difere em grande medida da vivência nas primeiras décadas do século XXI: o ritmo do tempo acelerado; a organização dos espaços impróprios ao silêncio; excesso de informação que nos atordoam, uma sensação de sentir as nossas heranças como "um fora do tempo". Em uma palavra, impossibilidade de transfiguração do real em matéria do pensamento.

Em "Experiência e pobreza", ensaio emblemático de 1933 inserido em uma coletânea designada Imagens do pensamento, Walter Benjamin (1892-1940) refletiu ${ }^{2}$ sobre o conceito de maneira instigante. Sublinha no texto a pobreza dos homens que retornaram da Primeira Guerra Mundial emudecidos, depauperados de experiência comunicável. E mais, de modo a questionar a rápida substituição da tradição pela emergência de uma sociedade fundada nos meios técnicos, nas

\footnotetext{
${ }^{2}$ Ver Benjamin (1999).
} 
invenções, convoca arquitetos, pintores, escritores para realizarem a tarefa de lembrar. Rememora, então, a tradição cultural acompanhado de James Sydney Ensor, pintor belga; Paul Klee, pintor suíço, Adolf Loos, arquiteto austríaco; Paul Scheerbart, escritor alemão; Jules Verne, escritor francês; Le Corbusier, arquiteto suíço, apena para citar alguns deles, como se mirássemos um caleidoscópio de múltiplas nacionalidades. Com os intelectuais, e a partir da produção cultural por eles criada na experiência possível do período entreguerras, o filósofo alemão refletiu sobre a contradição dos anos de 1930, época marcada por um tremendo desenvolvimento tecnológico, mas cuja pobreza cultural deixava traços inexoráveis na humanidade.

A pobreza da experiência, por essa visada de Benjamin, nos auxilia a observar a atual modernidade, por alguns designada pós-modernidade, de maneira cautelosa, pois, não raro, paira o deslumbramento desmedido em relação às novidades tanto quanto emergem os perigos do esquecimento das lembranças que nos constituem. Ainda, segundo os comentários de Benjamin, repara-se naquele ensaio a experiência mediada pelas diversas formas de expressão cultural, incluindo-se a narrativa, a escritura, a literatura, expressões culturais muito caras a esta exposição. E, nos interstícios dessas expressões, a infância é convocada para nos contar sobre história e "despropósitos".

\section{Infância: entre história e "despropósitos"}

Um livro, uma página de livro apenas, por menos ainda, uma simples gravura em um exemplar antigo, herdado talvez da mãe ou da avó, poderá fertilizar o terreno no qual a primeira e delicada raiz desse impulso começa a se desenvolver (Benjamin, 1984, p. 48).

Lembrar, como exercício do pensamento e como tarefa artística, consiste em uma atividade afeita ao poeta. De modo especial, a matéria literária elaborada por Manoel de Barros emerge com frequência da tarefa de rememorar a infância, não meramente como etapa cronológica da vida, mas na condição de um conceito referenciado aos restos, aos seres desprezados. Tal alegoria permite a alusão a certo conceito de história, ancorada nos detritos, tal como refletido por Walter Benjamin em muitos de seus trabalhos. Walter Benjamin, filósofo, ensaísta, crítico de arte, interessava-se pelos estudos da cultura e da história, abordando diversos temas, entre os quais se pode sublinhar a preocupação com a 
perda da experiência no homem, como visto anteriormente, e com sua capacidade de narrar (resgatar a sua história, a história) no mundo moderno. ${ }^{3}$ Nesse sentido, os exemplos mais ilustrativos são os ensaios "Experience and poverty" (1999) e "O narrador" (1987), escritos, respectivamente, em 1933 e em 1936. Da mesma forma, dedicou-se com paixão à filosofia da história, repensando os fundamentos do materialismo histórico e a própria concepção da história. É preciso ler cuidadosamente as suas teses em "Sobre o conceito de história", de 1940 (Benjamin, 1987), para acompanhar o movimento singular dessas reflexões. Ocorre que, mesmo em seus fragmentos literários, Benjamin surpreende o leitor com sutis inferências sobre a história.

Ensinam as teses, por exemplo, que a realidade deve ser lida nos mínimos detalhes, nos pequenos gestos, pois o fragmento o todo contém, sendo a possibilidade de sua apreensão o instante de um relâmpago. Considerando uma bela imagem escrita pelo filósofo, lembro que:

Quem pretende se aproximar do próprio passado deve agir como um homem que escava. Antes de tudo, não deve temer voltar sempre ao mesmo fato, espalhá-lo como se espalha a terra, revolvê-lo como se revolve o solo. Os fatos nada são além de camadas que apenas à exploração mais cuidadosa entregam aquilo que recompensa a escavação. E se ilude, privando-se do melhor, quem só faz o inventário dos achados e não sabe assimilar no terreno de hoje o lugar no qual é conservado o velho (Benjamin, 1987, p. 239).

De maneira análoga, Manoel de Barros convida o leitor a se aproximar da infância como dimensão privilegiada de acesso à história, quiçá via de acesso singular à reflexão sobre a condição humana. Não por acaso, alude a um "dom diferente" de apreender o mundo na infância, uma vez que os seres e os gestos desprezíveis ganham ali estatuto renovado. Em outras palavras, pelas lentes da infância, são alçados a obras do pensamento que trazem força e beleza à natureza:

\section{Obrar}

Naquele outono, de tarde, ao pé da roseira de minha avó, eu obrei. Minha avó não ralhou nem. Obrar não era construir casa ou fazer obra de arte. Esse verbo tinha um dom diferente. Obrar seria o

\footnotetext{
${ }^{3}$ Konder (1988) traça o retrato social da época em que viveu o filósofo, elaborando uma síntese de sua vida e de sua obra. Além desse estudo, conferir outras interpretações do conjunto da obra de Benjamin: Kramer (1994), Jobim e Souza (1994), Gagnebin (1994), Schiavoni (1989), Muricy (1987), Bolle (1989), Silva (2009), entre outros.
} 
mesmo que cacarar. Sei que o verbo cacarar se aplica mais a passarinhos. Os passarinhos cacaram nas folhas nos postes nas pedras do rio nas casas. Eu só obrei no pé da roseira da minha avó. Mas ela não ralhou nem. Ela disse que as roseiras estavam carecendo de esterco orgânico. E que as obras trazem força e beleza às flores. Por isso, para ajudar, andei a fazer obra nos canteiros da horta. Eu só queria dar força às beterrabas e aos tomates. A vó então quis aproveitar o feito para ensinar que o cago não é uma coisa desprezível. Eu tinha vontade de rir porque a vó contrariava os ensinos do pai. Minha avó, ela era transgressora. No propósito ela me disse que até as mariposas gostavam de roçar nas obras verdes. Entendi que obras verdes seriam aquelas feitas no dia. Daí que também a vó me ensinou a não desprezar as coisas desprezíveis. E nem os seres desprezados (Barros, 2003, s.p.).

Sublinham-se, portanto, algumas semelhanças de fundo entre o modo de refletir de Walter Benjamin e a maneira de poetizar de Manoel de Barros. Ademais, no conjunto da obra de ambos os autores, identificam-se temas que ora se aproximam da infância como esfera do despropósito deliberado, ora do exercício de pensar os restos da história, ora de um modo peculiar de inventar a partir da linguagem.

A referida possibilidade de criar despropósitos deliberados a partir da linguagem guarda proximidade com o jogo, atividade privilegiada dos personagens criados pelo poeta, que a radicalizam na condição de criança. Em Exercícios de ser criança (Barros, 1999), por exemplo, identificam-se despropósitos linguísticos a par de outras noções lúdicas, como a inversão de papéis entre quem ensina e aquele que aprende. Observem-se alguns desses exercícios:

\section{Exercícios de ser criança}

No aeroporto o menino perguntou: - E se o avião tropicar num passarinho? $\mathrm{O}$ pai ficou torto e não respondeu. $\mathrm{O}$ menino perguntou de novo: - E se o avião tropicar num passarinho triste? A mãe teve ternuras e pensou: será que os despropósitos não são mais carregados de poesia do que o bom senso? Ao sair do sufoco o pai refletiu: - Com certeza, a liberdade e a poesia a gente aprende com as crianças. E ficou sendo (Barros, 1999, p. 469).

Manoel de Barros opera no viés do jogo em, pelo menos, duas dimensões. De uma parte, tem-se o jogo linguístico, que se configura no uso deliberado do neologismo tropicar: expressão polissêmica, que ganha 
existência e pleno sentido no discurso poético. De modo a ampliar a invenção, lê-se: "E se o avião tropicar em um passarinho triste?" De modo análogo e nas fronteiras do uso da imaginação criadora pela linguagem, imagina-se um passarinho triste, repleto de atributos humanos, capaz de, pelas mãos do poeta, ser atingido fatalmente por um avião. $O$ segundo nível do jogo emerge da posição às avessas do lugar atribuído à criança: nesse exercício de ser criança, ela força o adulto a pensar, a aprender com os seus despropósitos, pois "- Com certeza, a liberdade e a poesia a gente aprende com as crianças. E ficou sendo."

Acresça-se a ampliação da compreensão do jogo para a percepção do material literário elaborado por Manoel de Barros nos limites deste estudo.

Em Exercícios de ser criança, por exemplo, compreende-se que as crianças dão existência às coisas que inventam. Brincar, para elas, adquire um significado essencial. Não se trata de pura imitação nem, apenas, de contribuir para amadurecer e desenvolver as faculdades mentais. ${ }^{4}$ Durante a brincadeira, a criança tem a possibilidade de tirar os objetos de sua função reificada, tão própria das sociedades de consumo. Agindo sobre aqueles objetos no ato de brincar, a criança imprime-lhes, fundamentalmente, um novo significado, que contribui para afirmar o lugar de quem produz - e não somente reproduz - cultura. Eis o que acrescenta Benjamin: "Sem dúvida, brincar significa sempre libertação. Rodeadas por um mundo de gigantes, as crianças criam para si, brincando, o pequeno mundo próprio" (Benjamin, 1984, p. 64).

Importa sublinhar, em acréscimo, no conjunto dos poemas analisados, a presença de alguns temas relacionados ao universo de interesse infantil: restos de objetos que se tornam brinquedos, objetos antigos, passarinhos, lesmas, desperdícios, latas, sucatas. Os temas em destaque lembram uma notável reflexão de Walter Benjamin sobre a possibilidade de a criança produzir cultura a partir de objetos em desuso e aparentemente inúteis. Vale a pena acompanhar o pensamento do autor:

É que as crianças são especialmente inclinadas a buscarem todo local de trabalho onde a atuação sobre as coisas se dê de maneira visível. Elas sentem-se irresistivelmente atraídas pelos destroços que surgem da construção, do trabalho no jardim ou em casa, da atividade do alfaiate ou do marceneiro (Benjamin, 1984, p. 77).

\footnotetext{
4 Pressupostos que têm coroado o caráter positivista e mecanicista da Psicologia do Desenvolvimento. A este respeito, ver Jobim e Souza (1996). O artigo aprofunda a compreensão do desenvolvimento da criança a partir de uma teoria crítica da cultura.
} 
Ensina o filósofo que, a partir da relação com os destroços, a criança está muito mais interessada em criar um contato próprio com o mundo que a cerca do que imitar uma lógica que concerne à visão do adulto, engendrando para si, dessa forma peculiar, a possibilidade de produzir uma cultura que efetivamente lhe pertença. De maneira análoga, os temas presentes nos poemas de Manoel de Barros, que reconhecidamente trazem para o primeiro plano a criança, podem oferecer ao leitor múltiplas possibilidades de apropriação em diálogo com personagens crianças que subvertem a ordem estabelecida, e, por esse viés, possibilitam o acesso à imaginação criadora. Em uma chave semelhante, Vygotsky (1987) também salientou a relevância da imaginação e da arte no período que se convencionou denominar infância. Segundo o autor, a dicotomia entre fantasia e realidade consistiria na redução da possibilidade de se exercitar a imaginação criadora, pois a fantasia não se oporia necessariamente à realidade. Em outras palavras, bem poderia ser pensada como uma maneira outra de se penetrar no real e percebê-lo por meio de um ângulo renovado.

A importância do exercício por meio da imaginação criadora é recorrente na produção literária de Manoel de Barros. Verifica-se, porém, que o poeta, ao trazer para o primeiro plano o modo de habitar o mundo pela criança, que inventa, sonha, cria despropósitos, potencializa os jogos de linguagem, as inversões, as estratégias literárias, isto é, opera a reconfiguração estética do próprio material ficcional. Assim, se lê em:

\section{A menina avoada}

Foi na fazenda de meu pai antigamente. Eu teria dois anos; meu irmão nove. Meu irmão pregava no caixote duas rodas de lata de goiabada. A gente ia viajar. As rodas ficavam cambaias debaixo do caixote: uma olhava para a outra. Na hora de caminhar as rodas se abriam para o lado de fora. De forma que o carro se arrastava no chão. Eu ia pousada dentro do caixote com as perninhas encolhidas. Imitava estar viajando. Meu irmão puxava o caixote por uma corda de embiar. Mas o carro era diz-que puxado por dois bois. Eu comandava os bois: - Puxa, Maravilha! - Avança, Redomão! Meu irmão falava que eu tomasse cuidado porque Redomão era coiceiro. As cigarras derretiam a tarde com seus cantos. Meu irmão desejava alcançar logo a cidade - Porque ele tinha uma namorada lá. A namorada do meu irmão dava febre no corpo dele. Isso ele contava. No caminho, antes, a gente precisava de atravessar um rio inventado. Na travessia o carro 
afundou e os bois morreram afogados. Eu não morri porque o rio era inventado. Sempre a gente só chegava no fim do quintal. E meu irmão nunca via a namorada dele - Que diz-que dava febre em seu corpo (Barros, 2010, p. 470-471).

Se a experiência e a história são, de fato, derivadas da fratura entre a infância do homem e a emergência da linguagem, como sublinha o filósofo Agamben (2005), é possível que esse tipo de ruptura evidencie-se ainda mais na literatura. A obra poética de Manoel de Barros, como examinada nos limites deste ensaio, opera fraturas, deslocamentos, em relação à linearidade da linguagem comunicativa, por um lado. Por outro, ao acentuar a infância como dimensão latente da humanidade, o poeta permite-nos compreender as condições segundo as quais a linguagem literária, protagonizada por personagens crianças, potencializa o acesso à experiência e à história, na linha das considerações formuladas por Agamben (2005). Além disso, Manoel de Barros acentua ainda mais a ruptura entre a infância do homem e a emergência da linguagem, ao trazer a infância como potência, e não como mera etapa da vida biológica, como asseveram, em grande medida, os pressupostos ancorados na psicologia positivista e mecanicista do desenvolvimento.

Por último, Exercícios de ser criança (1999) e Memórias inventadas: a infância (2003), de Manoel de Barros, permitiram-nos desenvolver reflexões instigantes sobre a relação entre literatura, infância e experiência, com especial ênfase no protagonismo das crianças e em sua capacidade de colocar a realidade pelo avesso, de filosofar. Ademais, evidenciaram estratégias literárias inusitadas, capazes de causar estranhamento em relação ao caráter meramente descritivo e comunicativo da linguagem cotidiana. Talvez, como sugere Manoel de Barros, seja essa a dimensão mais urgente a ser resgatada no contexto da sociedade brasileira contemporânea. Com a literatura, com a infância, com a experiência.

\section{Referências}

AGAMBEN, Giorgio (2005). Infância e história: destruição da experiência e origem da história. Belo Horizonte: UFMG.

BAKHTIN, Mikhail (1994). Marxismo e filosofia da linguagem. São Paulo: Hucitec. BARROS, Manoel (1999). Exercícios de ser criança. Rio de Janeiro: Salamandra. 
BARROS, Manoel (2003). Memórias inventadas: a infância. São Paulo: Planeta.

BARROS, Manoel (2010). Poesia completa. São Paulo: Leya.

BENJAMIN, Walter (1984). Reflexões: a criança, o brinquedo e a educação. São Paulo: Summus.

BENJAMIN, Walter (1987). Obras escolhidas I: magia e técnica, arte e política. São Paulo: Brasiliense.

BENJAMIN, Walter (1933/1999). Experience and poverty. In: JENNINGS, Michael W.; EILAND, Howard; SMITH, Gary (Eds.). Walter Benjamin - selected writings: 1927-1934. Harvard: Harvard College. p. 731-735. v. 2.

BOLLE, Willi (1989). Pensamento privilegiado e cultura de massas: tradição e modernidade em Walter Benjamin. Linha d'água, n. 6, p. 13-27.

GAGNEBIN, Jean Marie (1994). História e narração em Walter Benjamin. São Paulo: Perspectiva: FAPESP; Campinas: UNICAMP.

JOBIM E SOUZA, Solange (1994). Infância e linguagem: Bakhtin, Vygotsky e Benjamin. Campinas: Papirus.

JOBIM E SOUZA, Solange (1996). Re-significando a psicologia do desenvolvimento: uma crítica à pesquisa da infância. In: KRAMER, Sonia; LEITE, Maria Isabel (Orgs.). Infância: fios e desafios da pesquisa. Campinas: Papirus.

KONDER, Leandro (1988). Walter Benjamin: o marxismo da melancolia. Rio de Janeiro: Campus.

KRAMER, Sonia (1994). Por entre as pedras: arma e sonho na escola. São Paulo: Ática.

MURICY, Katia (1987). Benjamin: política e paixão. In: CARDOSO, Sergio et al. (Orgs.). Os sentidos da paixão. São Paulo: Companhia das letras.

SCHIAVONI, Giulio (1989). Frente a um mundo de sueño: Walter Benjamin y La enciclopédia mágica de la infância. In: BENJAMIN, Walter. Escritos: la literatura infantil, los niños y los jóvenes. Buenos Aires: Nueva Vision.

SILVA, Márcia Cabral da (2009). Infância: apontamentos sobre experiência e formação. In: JOBIM e SOUZA, Solange; KRAMER, Sonia (Orgs.). Política, cidade e educação: itinerários de Walter Benjamin. Rio de Janeiro: Contraponto: PUC-Rio.

VYGOTSKY, Lev Semenovich (1987). La imaginacion y el arte en la infância. México: Ediciones y Distribuiciones Hispanicas.

Recebido em setembro de 2014.

Aprovado em fevereiro de 2015. 


\section{resumo/abstract}

\section{Literatura e infância: entre filosofia, história e "despropósitos"}

Márcia Cabral da Silva

Neste estudo, sublinham-se algumas reflexões no âmbito da relação entre literatura, infância e experiência. De modo específico, almeja-se pensar sobre a dimensão filosófica da linguagem em diálogo com obras literárias contemporâneas que trazem ao primeiro plano a infância. Por um lado, opera-se uma reflexão sobre a relação entre ficção e infância, com especial ênfase na produção protagonizada por personagens crianças e em sua capacidade de ver a realidade por outra perspectiva, de filosofar. Por outro, enfatiza-se o exame de estratégias literárias capazes de causar estranhamento em relação ao caráter descritivo e comunicativo da linguagem cotidiana. Para desenvolver o exame, privilegiam-se as seguintes obras: Exercícios de ser criança (1999) e Memórias inventadas: a infância (2003), de Manoel de Barros.

Palavras-chave: infância, experiência, Manoel de Barros.

\section{Literature and childhood: between philosophy, history and nonsense}

Márcia Cabral da Silva

In this paper we emphasize some reflections in the context of the relationship among literature, childhood and experience. Specifically, the aim is to think about the philosophical dimension of language in dialogue with contemporary literary works that focus on childhood. On one hand, we reflect on the relationship between fiction and childhood, with special emphasis on the books that have children as main characters that have an ability to see the reality from another perspective, to philosophize. On the other hand, we emphasize the examination of literary strategies capable of causing perplexity in relation to the descriptive and communicative character of everyday language. In order to develop the study, the focus is on the following works: Exercícios de ser criança (1999) and Memórias inventadas: a infância (2003), by Manoel de Barros.

Keywords: childhood, experience, Manoel de Barros. 